Technical Note

\title{
Rock mass characterization for shallow granite by integrating rock core indices and seismic velocity
}

\author{
Daming Lin ${ }^{1}$, Renmao Yuan ${ }^{2}$, Yanjun Shang ${ }^{3}, \mathrm{Kun} \mathrm{Li}^{3}$
}

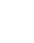

1. Research Institute of Highway, Ministry of Transport, Beijing 100088, China

2. Key Laboratory of Active Tectonics and Volcanoes, Institute of Geology, China Earthquake Administration, Beijing 100049, China

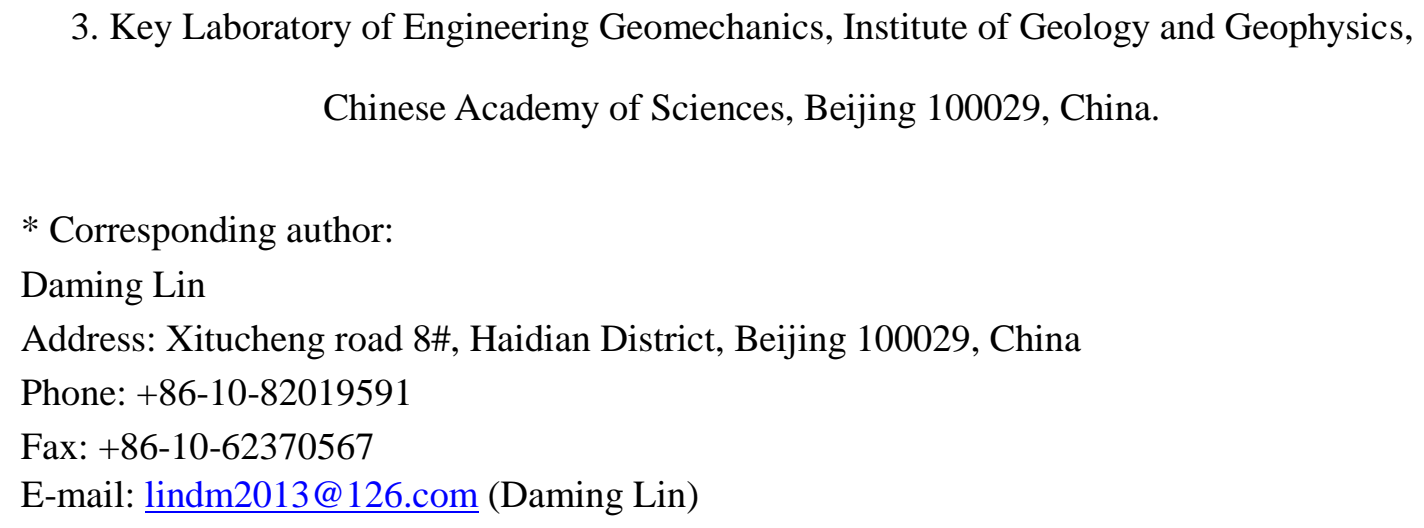




\section{Introduction}

The validity of rock mass classification systems often depends on geological conditions. One such system is the Rock Quality Designation $(R Q D)$ system, which accounts for only the frequency of jointing within a rock mass. The Rock Mass Rating [1] and $Q$ systems [2] used $R Q D$ as a measurable parameter and considered factors such as the intact rock strength, joint spacing, joint condition, field stress, joint sets and groundwater. The GSI [3, 4] method assesses the lithology, structure and condition of discontinuity surfaces in the rock mass.

Many scholars $[3,5,6]$ thought that geophysical methods, which are non-invasive and non-destructive methods to collect information on the heterogeneous subsurface, can be used as an initial assessment for engineering sites to optimize a site's investigation program. Seismic refraction can be used to assess the site's condition, rock mass structure, and so on [7].

Empirical relationships between seismic properties and the mechanical behavior of rock masses have been studied by different researchers [8,9]. Barton [2] found that a corresponding relationship exists among seismic wave velocity, electrical resistivity and rock density (Fig. 1). Sjögren et al [10] performed a comprehensive investigation, and summarized the correlations between the seismic velocities obtained from refraction surveys and the joints measured in drill cores. Combining geophysical data and geological drilling information can improve the methods that are used to characterize rock masses [11]. Choi et al. [12] derived some rock mechanical parameters, such as fracture frequency and rock quality designation $(R Q D)$, according to compressional wave velocity values $\left(V_{p}\right)$. An average regression curve was generated for different rock types.

A total of 278 drill holes (with a total rock core length of $8968.7 \mathrm{~m}$ ) and twelve geophysical survey lines (with a total length over $7000 \mathrm{~m}$ ) were created as a part of geological investigation by the China Spallation Neutron Source (CSNS). During the designation of twelve geophysical survey lines, the main principle is that the geophysical lines are close to the drilling hole and to cover the main structural area (such as ZZK105, ZZK99, ZZK94, ZZK10 in the fracture zone) as more as possible, 
which makes that this paper can collect the better scientific data from field (Fig. 2).

A 3-D geological-geophysical model that is based on data from the cores and CSNS geophysical survey is constructed in this paper. The $R C I$ (rock core index) and seismic velocities are then assigned in every subdivided grid. An empirical relationship between the $R C I$ and seismic velocity is analyzed and established in the grid. Different grid properties are matched in the GOCAD 3-D model based on these drilling core and geophysical data, and then the properties are analyzed and the empirical relationships are established.

This paper introduces a method to quantitatively analyze rock mass structures using geophysical parameters, which is helpful for the prevention of geological disasters along the highway in the granitic area.

\section{Study on granitic rock mass structures}

\subsection{Engineering background of the case study}

The CSNS is a major national science and technology infrastructure project, the laboratory foundation of which is located in an area with slightly weathered granite (Fig. 2). A total of 278 drill holes and twelve geophysics lines were created because of the high standard of the foundation (the annual differential settlement of the tunnel foundation should be less than $0.5 \mathrm{~mm}$ and the annual average settlement should be less than $1 \mathrm{~mm})$.

The construction site is approximately 400 acres. Most of the drilling holes are approximately $15-90 \mathrm{~m}$ in depth (30-80 $\mathrm{m}$ in the main equipment area). A considerable amount of data from the rock mechanics and physical experiments were obtained. At the same time, many drilling holes are opened on the geophysics lines (such as ZZK104, ZZK105 et al). In this study, the data from the drilling holes and geophysical investigation were combined to evaluate the features of the rock mass.

\subsection{Evaluation of granitic rock mass quality based on the RCI}

\subsubsection{RQD and RCI}

The most common characterization of rock mass structures is the rock quality 
designation $(R Q D)$, which is an intuitive feature and can be tested simply. However, recognizing rock structures in drilling cores becomes difficult at greater depths, which means that the $R Q D$ often cannot exactly describe the structural features of rock mass. For example, the $R Q D$ is 100 when the average length of the rock core is $120 \mathrm{~cm}$ or 45 $\mathrm{cm}$ according to Table 1 (ZZK2, ZZK41), but the cores have quite different properties, such as the depth, seismic velocity and $U C S$. The $R Q D$ varies sharply for different rock mass structures (from 100 to 0 in ZZK41 and ZZK14) with the same boundary of 10 $\mathrm{cm}$.

To exactly illustrate underground information, this paper considers reported results $[2,13,14]$ and defines the Rock Core Index $(R C I)$ based on the core length with six grades (1 3 cm, 3 10 cm, 10 30 cm, 30 50 cm, 50 100 cm and longer than $100 \mathrm{~cm}$ ) ration to the length unit (2.5m for CSNS) of research, which can described as follows:

$$
R C I=C_{r 1}+3 C_{r 3}+1 C_{r 10}+30 C_{r 30}+50 C_{r 50}+100 C_{r 100}
$$

where $C_{r 1}, C_{r 3}, C_{r 10}, C_{r 30}, C_{r 50}$ and $C_{r 100}$ are the proportion of each core length for 1-3 $\mathrm{cm}\left(C_{r 1}\right), 3-10 \mathrm{~cm}\left(C_{r 3}\right), 10-30 \mathrm{~cm}\left(C_{r 10}\right), 30-50 \mathrm{~cm}\left(C_{r 30}\right), 50-100 \mathrm{~cm}\left(C_{r 50}\right)$ and over $100 \mathrm{~cm}\left(C_{r 100}\right)$. According to formula (1), the range of $R C I$ is $0-100$.

For every round drilling trip, the accumulative core length is $1.25 \mathrm{~m}$ in CSNS. Two return times $(2.5 \mathrm{~m})$ are taken as the length unit in this study (in chapter 2.3.1, $2.5 \mathrm{~m}$ is also used as the computed length size of the grid unit after considering the precision of geophysical interpretation).

For example, assuming the cumulative length of a core with a grade of $10-30 \mathrm{~cm}$ is $100 \mathrm{~cm}$ and the cumulative length of a core with a grade over $100 \mathrm{~cm}$ is $150 \mathrm{~cm}$, the $C_{r 30}$ is 0.4 , and $C_{r 100}$ is 0.6 . Thus, $R C I\left(=30 C_{r 30}+100 C_{r 100}\right)$ is 72 according to formula (1) while grades for other core length are 0 .

Weathered crust was also classified into six different grades that correspond to different RCIs to describe the weathering diversities. In order to analysis the features of drilling cores with different granitic rock mass structures and different weathered level, Fig. 3 takes slightly weathered granite for example. The horizontal axis is the $R C I$ and 
the vertical axis is the number of grids with the properties of slightly weathered granite. The total core length of slightly weathered granite in CSNS is $1567.5 \mathrm{~m}$. When $2.5 \mathrm{~m}$ is regarded as the computed length size, the data number is 627 . Interpolating the grid in the 3-D model shows that most of the RCI values for slight weathered granite are nearly 15 , whereas a few of them are nearly 80 .

\subsubsection{Relationship between RCI and RQD}

The RCI can be used as a comprehensive parameter to characterize the size and structural features of a rock block, which reflects its composition and relationships of the rock blocks. The samples in Fig. 4a and Fig. 4b show intact rock masses with few joints, which suggests fresh granite being disturbed by little tectonic activity. The core with few discontinuities is well interlocked. The melanocratic minerals, such as mica, have a fine glossiness [15]. The plagioclase is not kaolinized, which indicates that the site can be selected for constructing key engineering, such as a nuclear power plant. The $R Q D$ based on the core in both Fig. $4 \mathrm{a}$ and $4 \mathrm{~b}$, which show different mechanics, is $96 \%$, which indicates that different rock masses can have the same $R Q D$ value, the rock masses in Fig. 4a and Fig. 4b, which have the same $R Q D$ value, have obviously different $R C I$ values (68 for Fig. $4 \mathrm{a}$ and 54 for Fig. $4 \mathrm{~b}$ based on formula (1)).

The samples in Fig. 4c and 4d are poorly interlocked and heavily broken with small joint spaces $(<3 \mathrm{~cm})$. The drilling core rate is $30 \%-50 \%$, and the $R Q D$ is almost zero. However, the $R C I$ values are 13 for Fig. $4 \mathrm{c}$ and 0 for Fig. $4 \mathrm{~d}$ based on formula (1), which indicates the diversity of rock mass. Almost all the mica in the core is weathered, and the plagioclase is clearly kaolinized. The above information suggests that the $R C I$ is better to describe the structural features of a rock mass than the $R Q D$.

In this study, $2.5 \mathrm{~m}$ of drilling core (two return times) is regarded as the computed size to analyze the relationship between the $R C I$ and $R Q D$. Figure 5 shows the fitting line based on over $8000 \mathrm{~m}$ of drilling cores from the CSNS project, which is expressed by the following formulae:

$$
\begin{gathered}
R Q D=11.1 R C I-17.7 \quad\left(1.5946 \leq R C I \leq 10.6036, R^{2}=0.94\right) \\
R Q D=0.4 R C I+71 \quad\left(10.6036 \leq R C I \leq 72.5, R^{2}=0.20\right) \\
5
\end{gathered}
$$


According to the definition of $R Q D$ and $R C I$, they both have no actual physical sense, the difference between $R Q D$ and $R C I$ is the value boundary of rock core length. $R C I$ have six value boundaries (as Eq. 1) while $R Q D$ have only one $(10 \mathrm{~cm})$. Therefore, it is difficult to get the accurate corresponding relationship between $R Q D$ and $R C I$.

An obvious phenomenon for the boundary of $R C I=10$ is observed by authors. When $R C I$ less than 10 , the rock core reflects rock mass with interlocked or angular blocks formed by many intersecting discontinuity sets, the $R Q D$ correlated very well with $R C I$. Usually, the core length is range in 1-30. Based on Fig. 4, it can be found that the $R C I$ varies from 0 to 5 when the $R Q D$ is 0 . When the $R Q D$ varies from $10 \%$ to $100 \%$, it still exists many RCIs corresponding to one $R Q D$ (see the red circle in Fig. 5), which means that the $R C I$ is better than the $R Q D$ to describe the features of rock masses when $R C I$ less than 10. This phenomenon is well presented by Fig. 4.

When $R C I$ is more than 10 in the data from CSNS, these two parameters have little correlation (the $R^{2}$ between $R C I$ and $R Q D$ is only 0.20). For the data from CSNS, the length of most of drill cores is larger than $10 \mathrm{~cm}$ and less than $50 \mathrm{~cm}$ in this case. Based on the definition of $R Q D$ and $R C I$, Eq. (3) indicates that $R C I$ has a narrow advantage over $R Q D$ when $R C I$ is over 10 . In this situation, they can be used to illustrate the rock mass characterization independently because of the length of core over $10 \mathrm{~cm}$. And $R Q D$ can assist $R C I$ to study rock mass mechanics properties for intact rock specimens or massive with few discontinuities, very well interlocked.

The difference between $R Q D$ and $R C I$ is the value boundary of rock core length, while the value of $R Q D$ range between 0-100. Limited by the definition of $R Q D$ (which is used worldwide), the range of $R C I$ in Eq. (2) is 1.5946-10.6036, and 10.6036-72.5 in Eq. (3). Actually the value of $R C I$ is also range between $0-100$, the researchers thus think that relationship between these two parameters can be expressed by an empirical formula. If RCI is obtained based on Eq. (2), the value of which is only the rough or average value.

According to observations and analyses of different rock mass features in the CSNS project, relationship between the rock mass structure and the $R C I$ is summarized in Table 2. In fact, when $R Q D$ and $R C I$ are combined together to characterize the shallow 
granite, the underground geological information can be described more sufficiently. This approach is useful for site evaluation based on drilling cores.

\subsection{Integrated study of granitic rock mass structures based on the RCI and seismic} velocity in a 3-D model

\subsubsection{Data source}

Drilling core data and geophysical information could be integrated together in GOCAD, which serves as a powerful geological statistical analysis module by integrating various data sources (Table 3), to analyze the features of granitic masses. The analysis results were then input into the grid as the property data. The $8,968.7 \mathrm{~m}$ of drilling cores (with different lengths, different weathering zone, and different weathering degrees) could be used for weathering zone. The distribution of groundwater and the position of the aquifer could be used to analyze the hydro-geological conditions. A 3-D geological-geophysical model of the CSNS site was constructed (Fig. 6) by combining the 278 drilling holes, contour lines and seismic velocity data (Table 3 and Fig. 7). Here, the $R C I$ and seismic velocity are taken as the grid properties of the model. Thus, the corresponding spatial correlations of different geological and geophysical properties could be discussed.

Approximately 3,808,665 grids were generated in the model using Discrete Smooth Interpretation, which was developed by Mallet [16], in the 3-D model (Fig. 7). Every grid represents $5 \mathrm{~m}$ in the horizontal direction and $2.5 \mathrm{~m}$ in the vertical direction. During the meshing process, every grid was affiliated with the $R C I$ values and seismic velocities that were obtained from the geological and geophysical data sources. The collected data and the properties in the model were used to derive an empirical relationship by matching and modifying the properties in the model.

\subsubsection{Assumptions of the 3-D model}

The rock type (uniaxial strength and porosity), measurement depth, stress level and stress-induced anisotropy can influence interpretations of the $3-\mathrm{D}$ model $[17,18]$. The rock structures and geophysical characteristics of shallow granite are thoroughly 
described based on the field and experimental data in the 3-D model.

Only the main factors in this study were considered; minor factors were ignored. The drilling process, confining pressure, interpolation algorithm, and grid unit size are assumed to be ideal, as follows:

(1) The same drilling machine brand (XY101 brand drill, diamond brand of bit drilling) was used during the investigation, and a depth of $1.25 \mathrm{~m}$ was used for every drilling trip as the standard length. Differences in the core lengths are caused mainly caused by different geological structures.

(2) The investigation depth was no more than $200 \mathrm{~m}$. Most of the drilling depths were within $100 \mathrm{~m}$. Thus, the effect of crustal stress (<2 MPa) could be neglected. The drilling results show that no laminated rock mass or water-resisting layer exists in the study area. Differences in seismic velocity are mainly influenced by the rock mass structures.

(3) The geophone interval for refraction wave exploration was $2 \mathrm{~m}$ with a $12-\mathrm{m}$ shot interval.

\subsubsection{Quality of granitic rock mass based on the RCI and seismic velocity}

Sometimes, a fault zone that created extremely broken rock masses can be found in the site area. Seismic methods then can provide insight into discontinuity zones and obtain exact geometric properties for unstable bodies. Images of granitic rock mass structures at shallow depths can be provided by waveform modeling, which can achieve a resolution of meters, including specific fault segments.

Figure 8 shows representative geological profiles. In this figure, the $R Q D, R C I$ and seismic velocity are considered as parameters to characterize the granitic rock mass quality. The boundary between moderately and slightly weathered layers is obvious. According to this picture, the $R C I$ and weathered crust can be interpreted from consistent wave velocities. For the Quaternary soil, the $R C I$ is almost 0 and the seismic velocity is less than $1910 \mathrm{~m} / \mathrm{s}$. For fresh granite, the $R C I$ is greater than 50 and the seismic velocity is greater than $5904 \mathrm{~m} / \mathrm{s}$. The quantitative relationship between weathered granite and seismic velocity is shown in Table 4, which suggests a good relationship between the $R C I$ and seismic velocity. 
The cores in the fault zone at the CSNS project site are thinly laminated and cracked weak rocks with joint spacing $<1 \mathrm{~cm}$ (Fig. 8). The drilling core rate is lower than $30 \%$. The $R Q D$ and $R C I$ of the rock masses in the fault zone are lower than those of the surrounding rock masses. The $R Q D$ in the fault zone is almost 0 and the $R C I$ is less than 5. The distribution of weathered crust is the opposite of the seismic velocity, which shows that the depth of the slightly weathered granite is deeper than that of the surrounding rock.

\subsubsection{Integrated study of shallow granitic rock mass}

Approximately 3808665 grids were generated in the model according to Discrete Smooth Interpolation. Theoretically, 3,808,665 data points of RCIs and seismic velocities can be obtained, but most of these data are the product of interpolation. The results of indoor experiments are utilized in this study to obtain the empirical relationship between the $R C I$ and seismic velocity.

Geological and geophysical data from the CSNS project site were combined to describe the granite's features. Information on the rock mass can obtained during an early investigation stage according to the empirical relationship between the $R C I$ and seismic velocity if the engineer can obtain such parameters.

Analyzing the qualitative relationship between the $R C I$ and velocity data shows that these features (the velocity changes with increasing depth) are similar to those from the research by Barton [2] (Fig. 1). In situ experimental data are used to substitute for the Discrete Smooth Interpolation data to improve the validity of the research.

The indoor mechanic experiments (not interpolation value) were conducted based on 30 groups of cores in the engineering geophysics lab. The fitting relationship between the $R C I$ and $V p$ (seismic velocity of $P$ wave) is shown in Fig. 9. The formula can be expressed by equation (3):

$$
R C I=7.2 V p-6.7 \quad(V p \geq 0.93)
$$

An obvious linear relationship exists between the $R C I$ and the seismic velocity. According to formula (4), when the $R C I$ is 0 , the seismic velocity is approximately 0.93 $\mathrm{km} / \mathrm{s}$. The $R C I$ value increases with increasing seismic velocity. 


\section{Discussion}

Granite is widely distributed and comprises approximately $9 \%$ of the area of China. Weathered granitic crust in East and South China generally occurs at 20-60 m depth. Many engineering projects have been built in this granitic area. However, the influence of both weathering and interspersed rock dikes can lead to different fracture zones, which is especially important for the characterization and recognition of shallow granitic rock masses.

The geophysical features of rock mass structures are the features that describe the differential responses of rock masses with different structures during geophysical prospecting. A total of 278 boreholes (total length of the core is 8,968.7 m), and shallow geophysical exploration lines with a total length of $8,968.7 \mathrm{~m}$ were examined for the China Spallation Neutron Source (CSNS) project. All these data established a solid foundation for this study.

The 3-D model contains many parameters, including the rock type (uniaxial strength and porosity), the depth of measurement, and so on. The main factors (rock mass structure and weathering difference) were considered in this work to thoroughly study the rock structures and geophysical characteristics of the shallow granite, whereas insignificant factors (moisture content, joint roughness, seepage) were ignored. The drilling process, confining pressure, interpolation algorithm, and grid unit size were assumed to be ideal, as described in section 3.3. an indirect assessment of the geo-mechanical properties of rock masses. The data from the CSNS project presented a good correlation between the velocity and $R C I$ when the

\section{Conclusions}

The $R Q D$ is a conventional parameter to characterize rock cores with a boundary of $10 \mathrm{~cm}$. This paper classified rock cores and proposed the $R C I$ (Eq. 1) as a new parameter to help characterize rock masses based on $8,968.7 \mathrm{~m}$ of cores from the CSNS project. 
293 The relationship between the $R C I$ and the rock mass structure in the shallow granite (Eqs.

2942 and 3, and Fig. 5) and the correlations between the $R C I$ and $R Q D$ were derived.

295 Different features are analyzed for different $R C I$ range in this paper.

296 Rock mass structures and engineering geophysics are currently almost independent

297 disciplines. Equation (4) shows the correlations between geophysical properties and the

298 rock mass structures. This approach may improve the methods of quantitatively

299 analyzing rock mass structures using geophysical parameters.

300 Table 2 shows the features of drilling cores for different granitic rock mass

301 structures. Figure 3 indicates the grading curve between the RCI distribution and core

302 length grading curve for slightly weathered granite. If engineers discover different

303 quality rock masses, they can use a 3-D geological and geophysical model (i.e., the

304 CSNS) to integrate rock core indexes and seismic velocity to characterize faults or 305 fissures for shallow granite, as illustrated in Fig. 9.

\section{Acknowledgments}

308 This study was supported by the National Science Foundation of China (Grant No. 309 41302254), Chinese Special Funds for Major State Basic Research Project (Grant 310 No.2010CB732001), and the Western communication construction technology project 311 MOT (Grant No. 2014318365110; 2013318Q03030). We express our deep appreciation 312 to the reviewers for their helpful comments and suggestions. 


\section{References}

[1]. Archie GE. The electric resistivity log as aid in determining some reservoir characteristics. Trans. Amer. Inst. Min. Metall. Petrol. Eng. 1942;14(6): 54-61.

[2]. Barton N. Rock Quality, Seismic Velocity. Attenuation and Anisotropy. Oxford: Taylor \& Francis; 2007.

[3]. Bieniawski ZT. Engineering classification of jointed rock masses. Trans. S. Afr. Inst. Civ. Eng. 1973; 15: 335-344.

[4]. Edelbro C. Evaluation of rock mass strength criteria. PhD thesis. Lulea University of Technology. 2004.

[5]. Chen Y, Huang T. Rock physics. Beijing: science press; 2001. pp: 206-215.

[6]. Derie BM. Integration of geophysical methods for groundwater exploration in hard rock areas: application to Alla Valley, Eritrea, NE Africa. PhD thesis. Loughborough University, 2011.

[7]. Hoek E. Surface and Underground Project Case Histories. Elsevier, 2014, pp. 32-64.

[8]. Hoek E, Carranza-Torres C, Corkum B. Hoek-Brown failure criterion-2002 edition. Proceedings of the 5th North American Rock Mechanics Symposium. Toronto. 2002: 267-273. [9]. H Liu, J Liu, C Yu, J Ye, Q Zeng. Integrated geological and geophysical exploration for concealed ores beneath cover in the Chaihulanzi goldfield, northern China. Geophys. Prosp. 2006; 54(6): 605-621.

[10]. Huang R, Huo J. Quantitative analysis of rock mass block index for dam foundation of jinping I hydropower station. Chin J Rock Mech Eng. 2011; (3): 449-454.

[11]. Lin D, Sun Y, Zhang W, et al. Modifications to the GSI for granite in drilling. Bull Eng Geol Environ 2014; 73(4): 1245-1258.

[12]. Choi J, Ryu H, Lee I. Rock mass classification using electrical resistivity - an analytical study. J. Geophys. Eng. 2006; 4: 151-163.

[13]. Kaselow A, Shapiro SA. Stress sensitivity of elastic moduli and electrical resistivity in porous rocks. J. Geophys. Eng. 2004; 1: 1-11.

[14]. Linek M, Jungmann M, Berlage $\mathrm{T}$, et al. Rock classification based on resistivity patterns in electrical borehole wall image, J. Geophys. Eng. 2007; 4: 171-183. 
343 [15]. Mallet JL. GOCAD: a computer aided design program for geological applications. In:

344 Three-dimensional modeling with geoscientific information systems. Dordrecht: Springer; 1992.

345 pp. 123-141.

346 [16]. van Overmeeren RA. A combination of electrical resistivity, seismic refraction, and

347 gravity measurements for groundwater exploration in Sudan. Geophysics 1981; 46(9):

$348 \quad 1304-1313$.

349 [17]. Hoseinie SH, Aghababaei H, Pourrahimian Y. Development of a new classification

350 system for assessing of rock mass drillability index (RDI). Int J Rock Mech Min Sci. 2008; 45 :

$351 \quad 1-10$.

352 [18].Sjøgren B, Øfsthus A, Sandberg J. Seismic classification of rock mass qualities. Geophys.

353 Prosp. 2006;27(2): 409-442. 

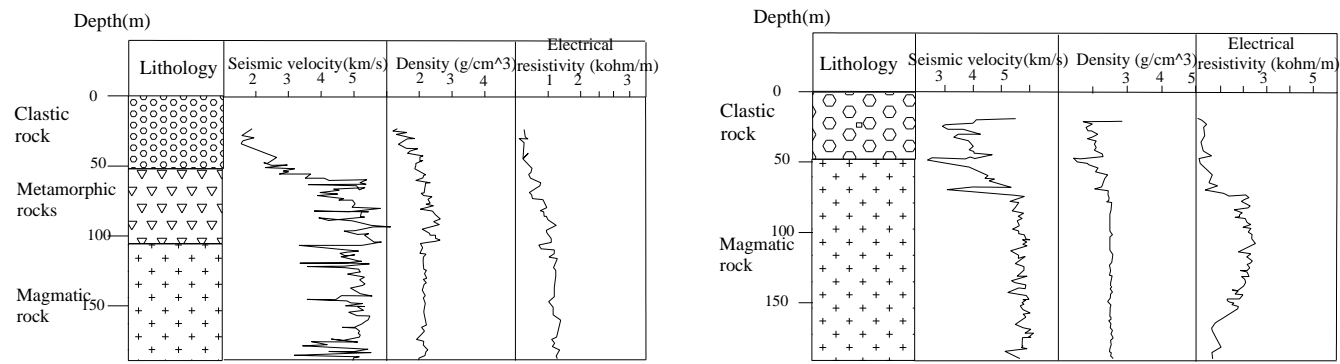

Fig. 1 Corresponding relationship among the seismic wave velocity, electrical resistivity and rock density (Barton, 2007)

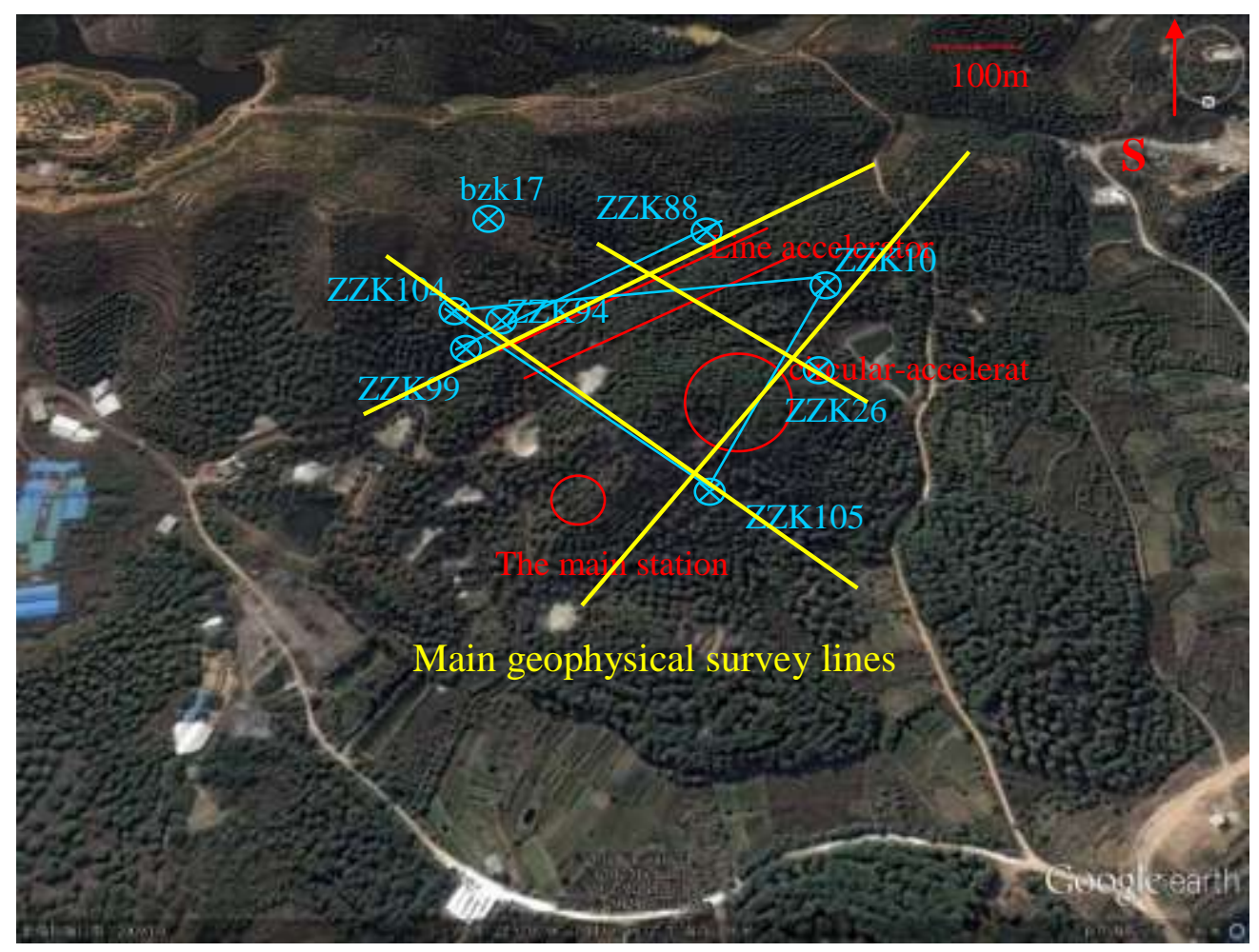

Fig. 2 Geomorphological map of the CSNS and key explored site 

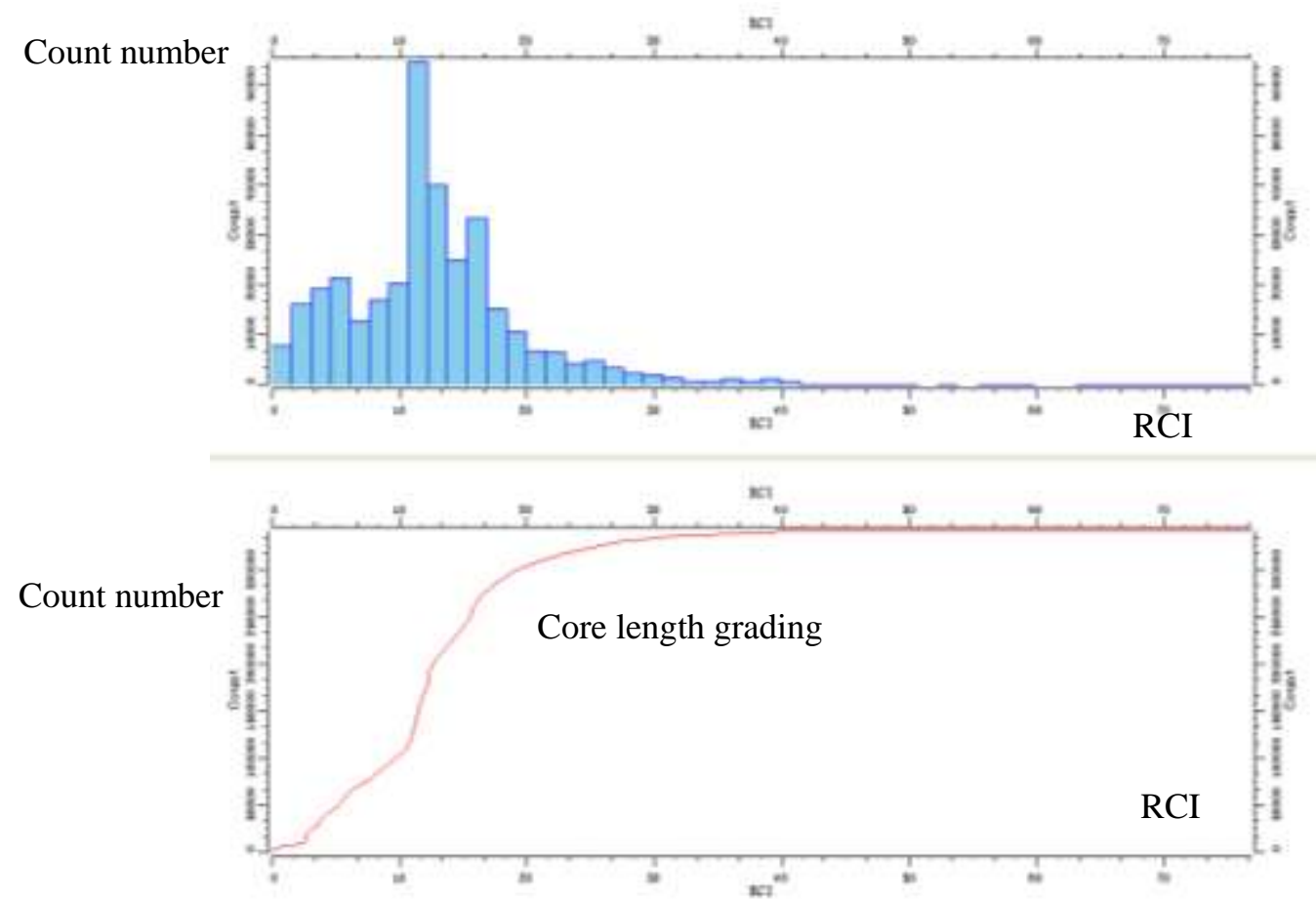

Fig. 3 RCI distribution and core length grading curve for slightly weathered granite

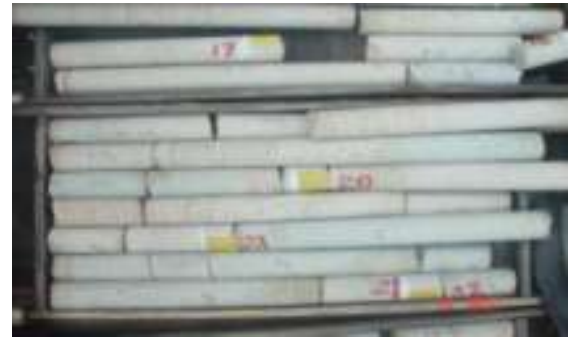

(a)

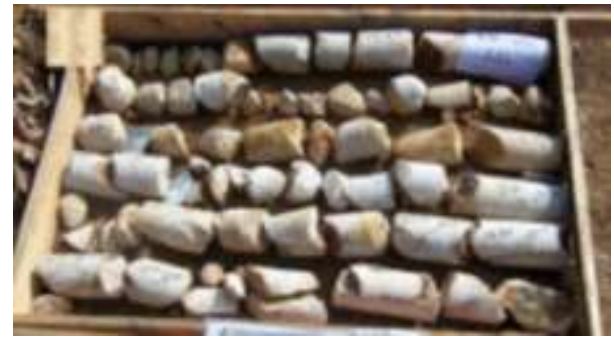

(c)

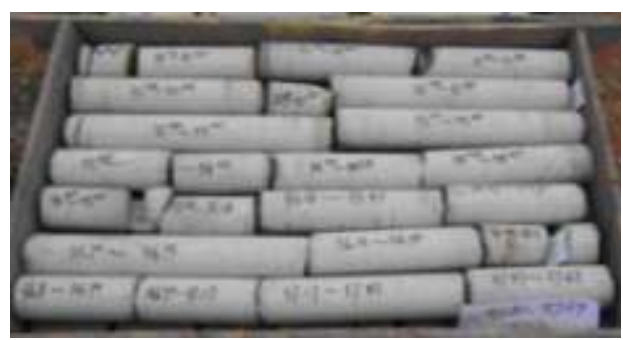

(b)

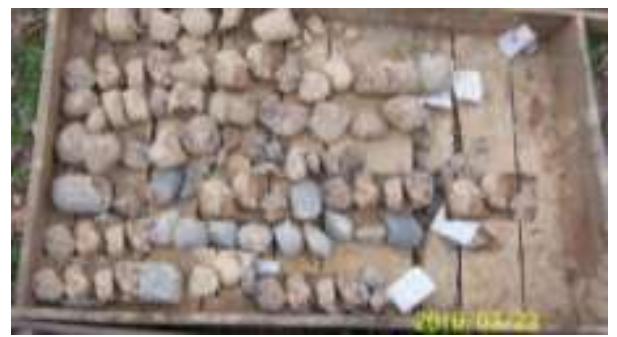

(d)

Fig. 4 RQD values based on the structures of rock masses

( $a$ and b show cores with RQDs over 95\%; $c$ and d show RQDs that are close to 0) 


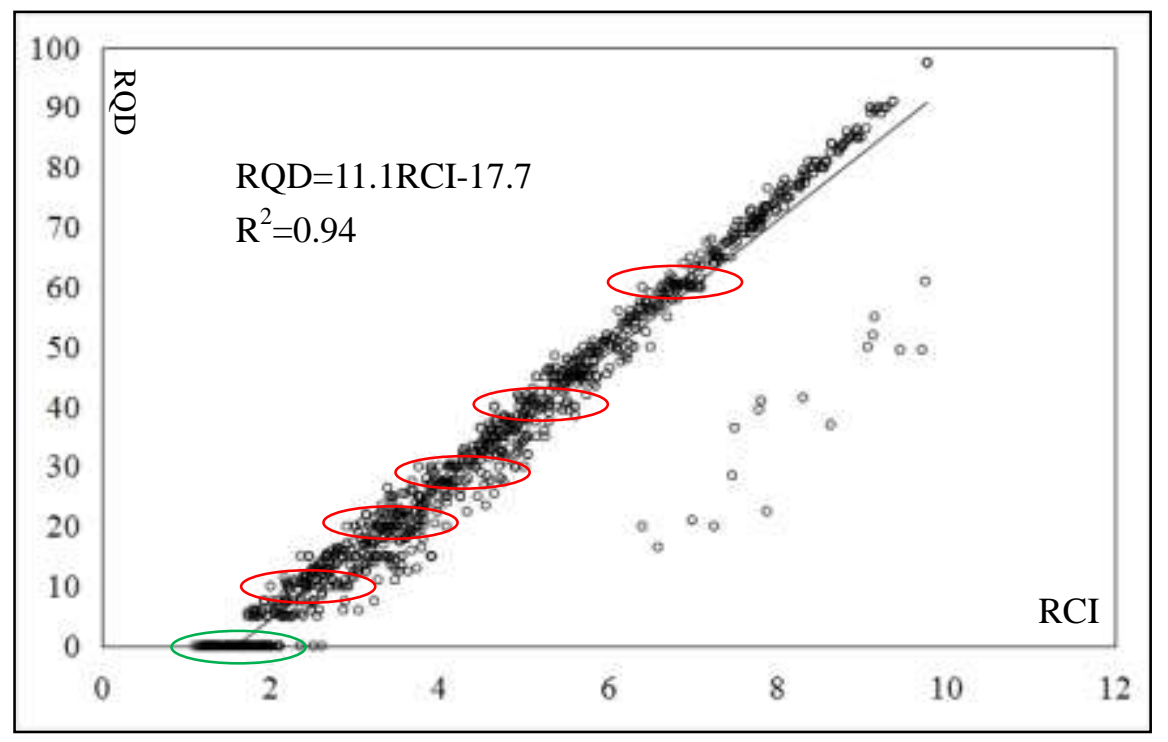

(a)

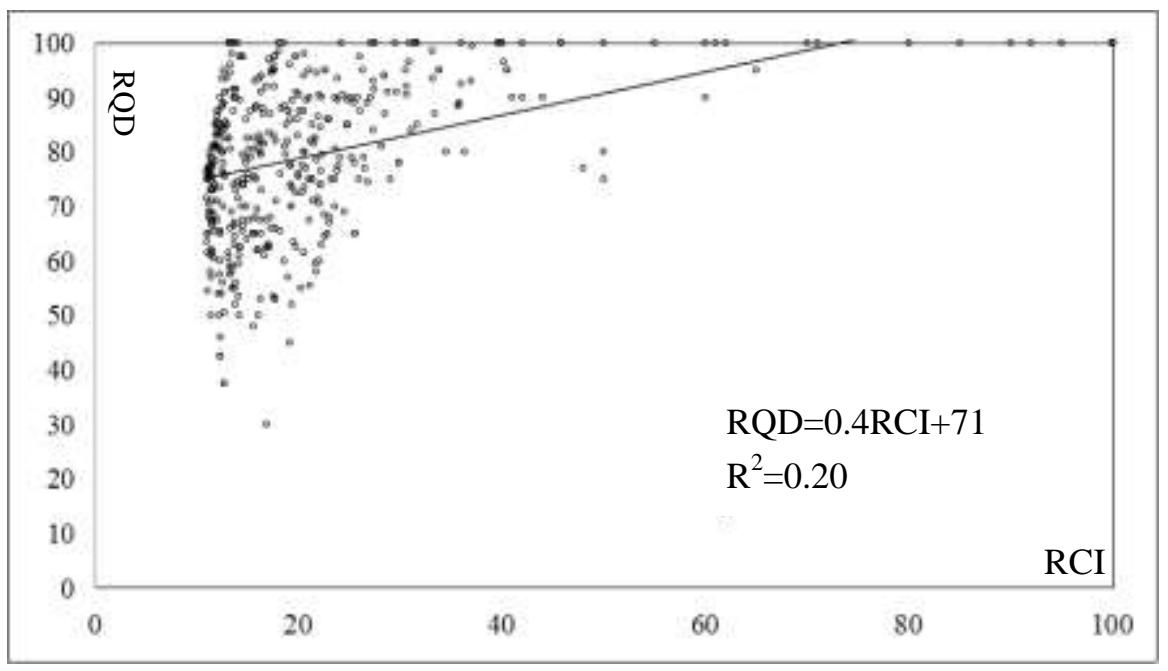

(b)

Fig. 5 Relationship between the RCI and RQD (a:RCI $\leq 10 ; \mathrm{b}: 10 \leq \mathrm{RCI} \leq 100)$

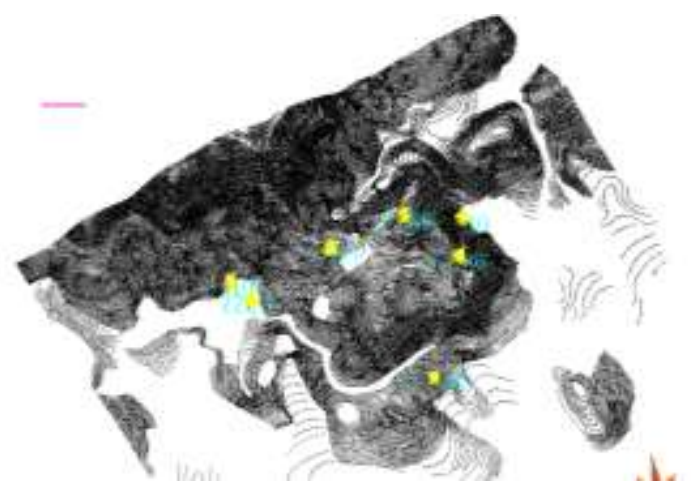

$\mathrm{a}$

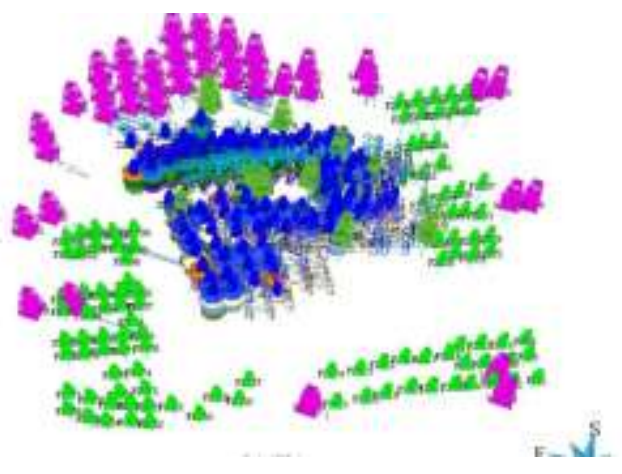

b 


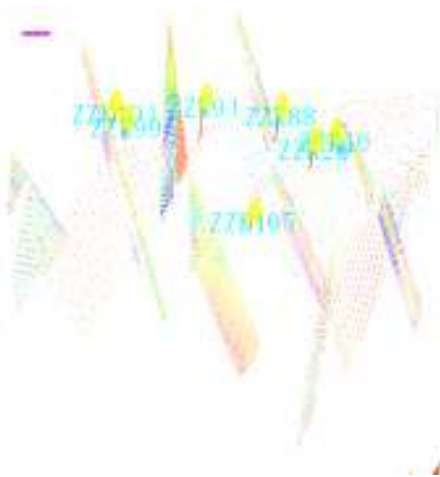

c

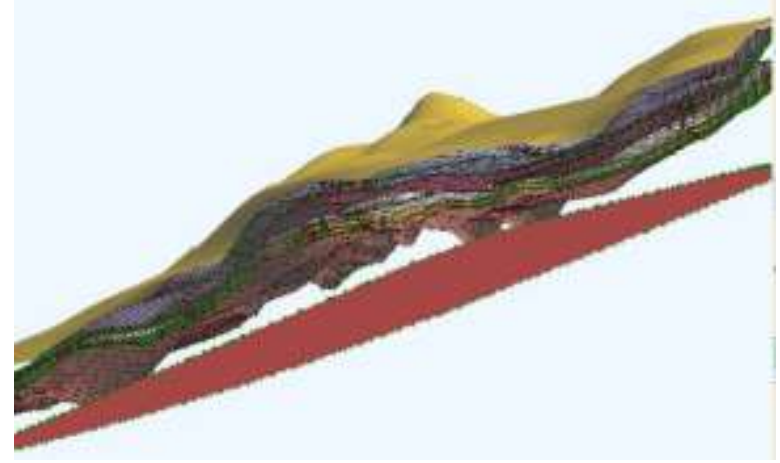

d

Fig. 6 Geological and geophysical data sources

(a: Elevation contour of CSNS in the study area; b: 278 drilling cores (with a total rock core length of $8968.7 \mathrm{~m}) ; \quad$ c: refracted wave exploration lines; d: weathered crust)

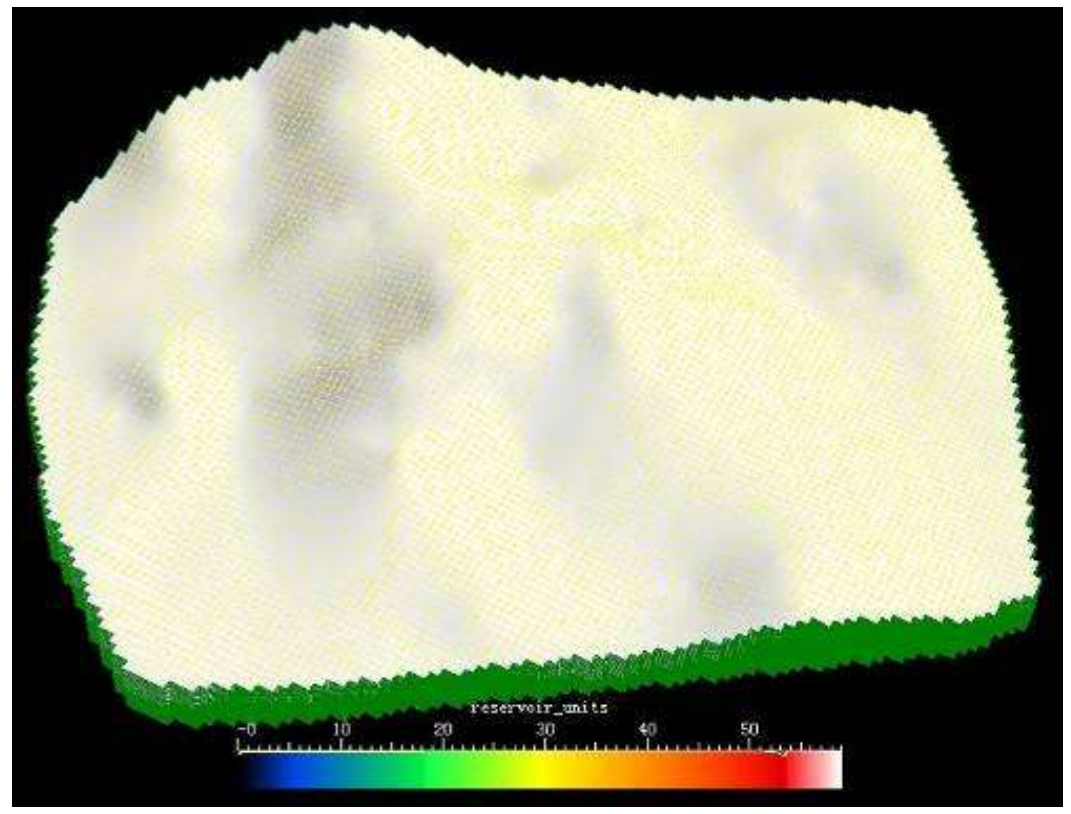

Fig. 7 3-D model for the CSNS project

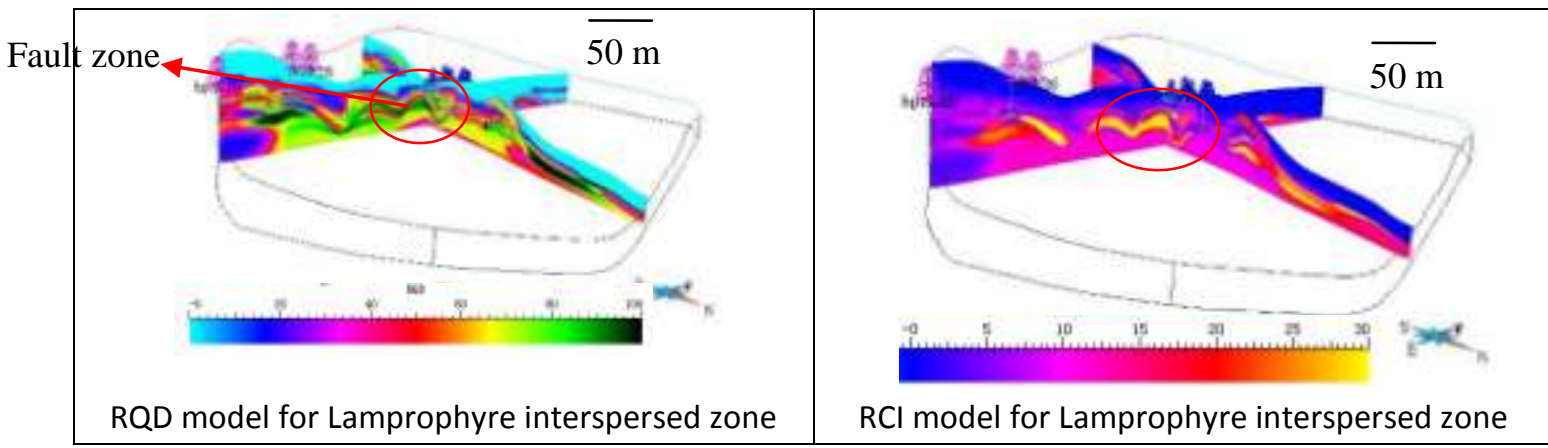




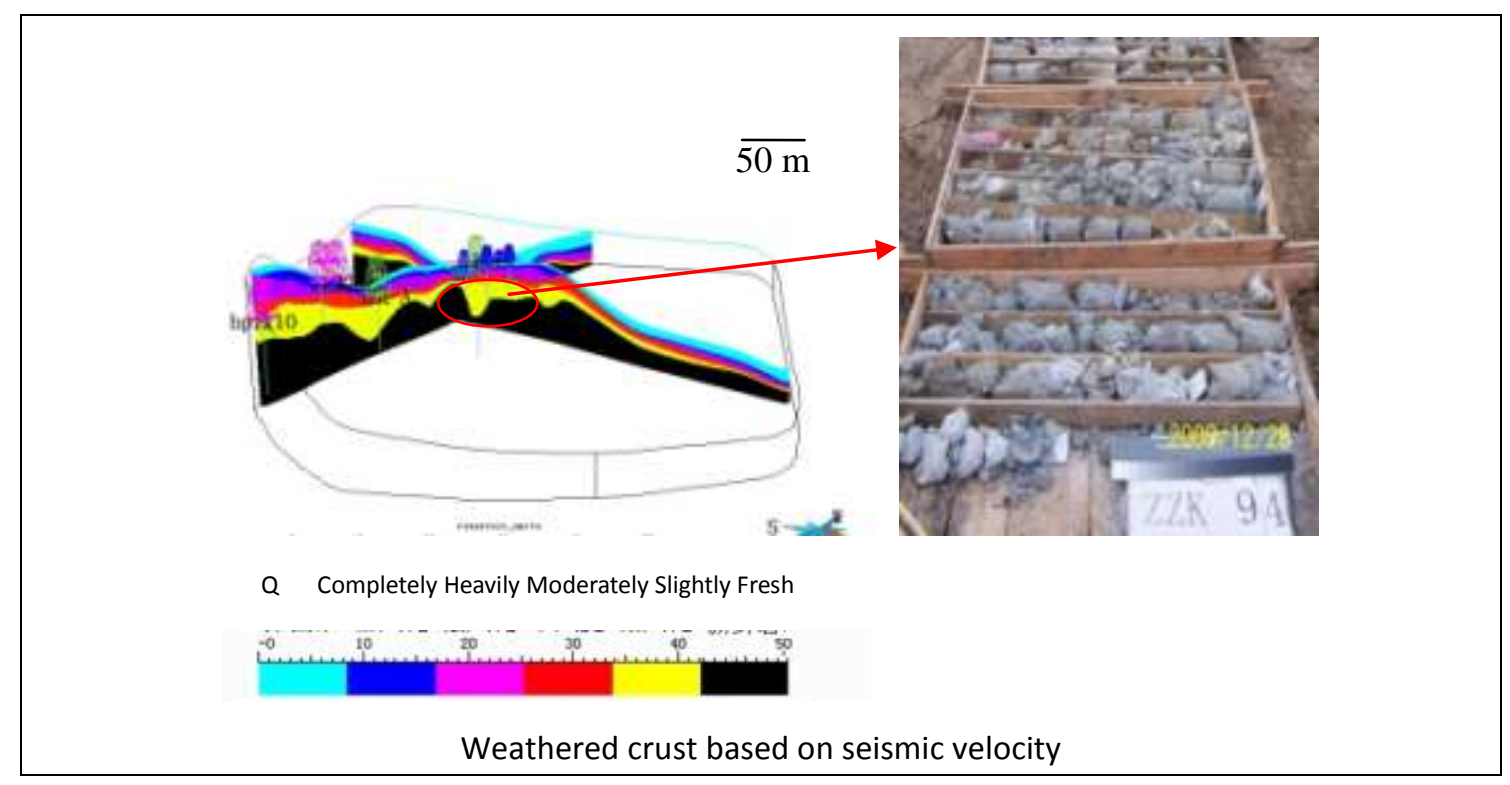

Fig. 8 Profile of CSNS in a 3-D geological and geophysical model

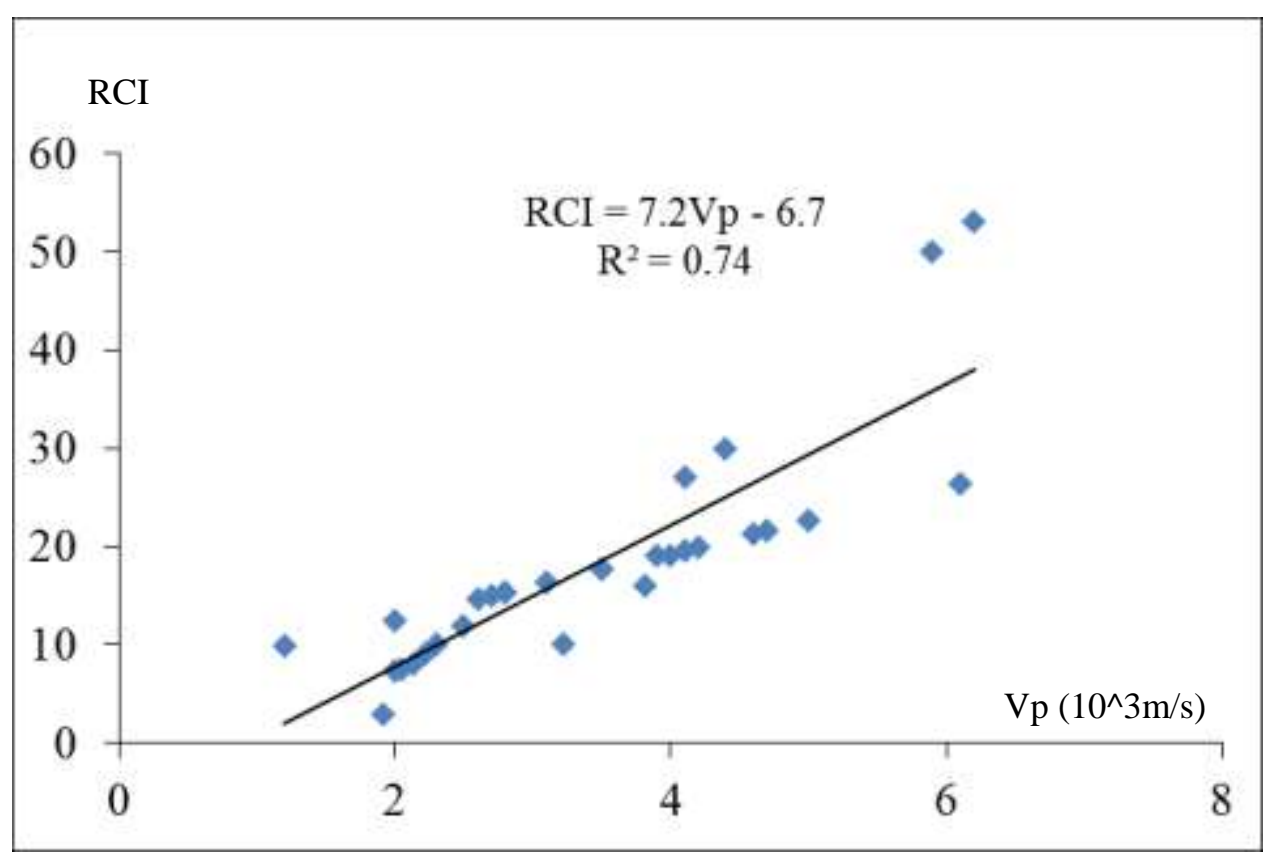

Fig. 9 Empirical relationship between the RCI and seismic velocity 
Table 1 Different properties for different rock masses

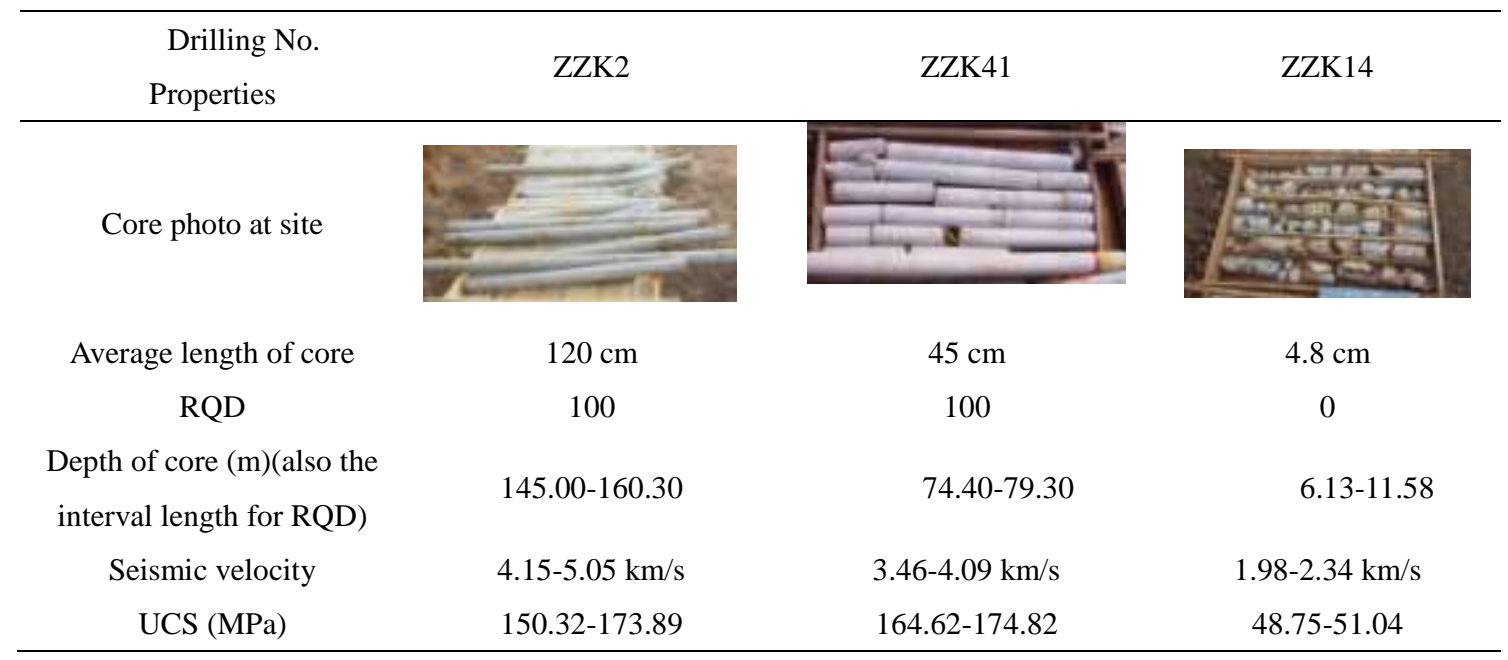

Table 2 Features of drilling cores with different granitic rock mass structures

\begin{tabular}{|c|c|c|c|c|c|}
\hline $\begin{array}{c}\text { Rock mass } \\
\text { structure }\end{array}$ & RCI & $\begin{array}{l}\text { RQD } \\
(\%)\end{array}$ & $\begin{array}{c}\text { Core rate } \\
(\%)\end{array}$ & Feature & $\mathrm{Kv}$ \\
\hline Intact & $50 \sim 100$ & 100 & Almost 100 & $\begin{array}{l}\text { Intact rock specimens or massive with } \\
\text { few discontinuities, very well interlocked. } \\
\text { Joint spacing }>100 \mathrm{~cm} \text {, and } \mathrm{RQD}=100 \text {. } \\
\text { Melanocratic minerals, such as mica, have } \\
\text { a fine glossiness, and the plagioclase is not } \\
\text { kaolinized. The crystallographic plane of } \\
\text { potassium feldspar is very fresh and } \\
\text { bright. }\end{array}$ & $>0.9$ \\
\hline Blocky & $30 \sim 50$ & $95 \sim 100$ & $90 \sim 100$ & $\begin{array}{l}\text { Very well interlocked undisturbed rock } \\
\text { mass that consists of cubical blocks from } \\
\text { three orthogonal discontinuity sets. The } \\
\text { joint spacing is } 30-100 \mathrm{~cm} \text {, and the RQD } \\
\text { is } 95-100 \text {. The feldspars are not weathered } \\
\text { and the quartzes are fresh. }\end{array}$ & $0.8-0.9$ \\
\hline $\begin{array}{c}\text { Very } \\
\text { Blocky }\end{array}$ & $10 \sim 30$ & $95 \sim 100$ & $80 \sim 95$ & $\begin{array}{l}\text { Interlocked and disturbed rock mass } \\
\text { with multifaceted angular blocks from } \\
\text { four or more discontinuity sets. The joint } \\
\text { spacing is } 10-30 \mathrm{~cm} \text {, and the RQD is } \\
95-100 \text {. Some of the mica is weathered } \\
\text { and the plagioclase is slightly kaolinized. } \\
\text { The structural planes occasionally show a } \\
\text { rusty tinge. }\end{array}$ & $0.6-0.8$ \\
\hline
\end{tabular}




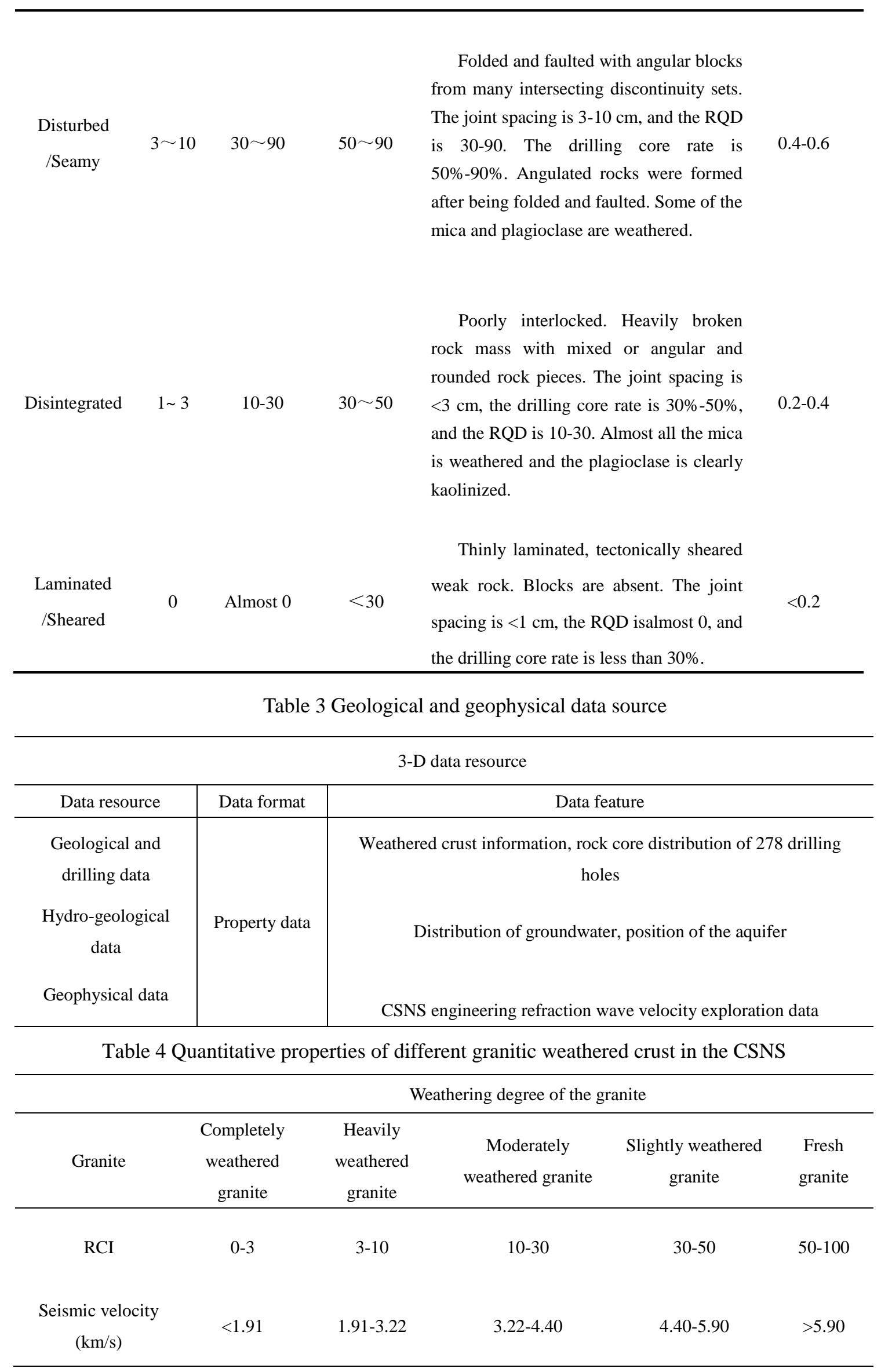

